\title{
Proof of delivery
}

\section{URLs}

Parkinson's: http://www.ncbi. nlm.nih.gov/entrez/dispomim. cgi?id $=168600$

Huntington disease: http:// www.ncbi.nlm.nih.gov/entrez/ dispomim.cgi?id=143100
Treating any disorder of the brain poses a special challenge owing to the difficulty of getting drugs across the blood-brain barrier. New work shows that implanting the brains of animal models with genetically engineered neural progenitor cells (NPCs) reduces some symptoms of Parkinson's disease, and might benefit other neurodegenerative disorders.

Parkinson's disease affects $\sim 1.5$ million people in the United States and is caused by the irreversible loss of dopaminergic neurons, which coordinate muscle movement and balance. We know that some molecules - such as glial cell linederived neurotrophic factor (GDNF) - can promote the regeneration of lost neurons, but delivering these agents to the brain by using viruses as carriers, or by injecting the molecule straight into the brain, could pose a risk to health or be inefficient. The group led by Soshana Behrstock and Clive Svendsen has hit on a different strategy of modifying cells to express GNDF. The engineered cells - human NPCs derived from fetal brains - were transferred into the area of the brain in which GDNF was needed in parkinsonian rats and ageing rhesus monkeys.

Remarkably, the protein produced by the cells remained active for up to 3 months and was transported to the substantia nigra, the brain region that degenerates in Parkinson's disease. In addition, the cells migrated across the affected region and led to increased fibre sprouting and survival of the host neurons.

Given that the effects of GDNF are not specific to the cells that are damaged in Parkinson's disease it is likely that these same cells could be used to treat other disorders, such as Huntington's disease and amyotrophic lateral sclerosis (ALS). Whether this therapy can be attempted in humans will depend on our devising a way to control the expression of GDNF in the engineered cells - in particular, to shut it off. The authors accomplished protein regulation in culture, but shut-off in animals proved more difficult and is being addressed in new experiments. Nevertheless, this work provides convincing evidence that stem cells are a valid vehicle for targeting drugs to less accessible tissues such as the brain in a safe and efficient way.

Tanita Casci, Senior Editor Nature Reviews Genetics

ORIGINAL RESEARCH PAPER Behrstock, S. et al. Human neural progenitors deliver glial cell line-derived neurotrophic factor to parkinsonian rodents and aged primates. Gene Ther. 15 December 2005 (doi:10.1038/sj.gt.3302679) FURTHER READING Jakel, R. J. Using human neural stem cells to model neurological disease. Nature Rev. Genet. 5, 136-144 (2004)| Svendsen, C. N. \& Langston, J. W. Stem cells for Parkinson disease and ALS: replacement or protection? Nature Med. 10, 224-225 (2004)

WEB SITE

Clive Svendsen's laboratory: http://www. waisman.wisc.edu/scrp/svendsen.html

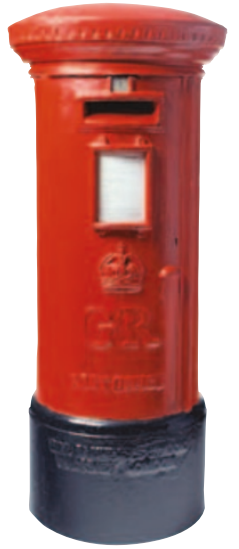

